\title{
Targeted Nanotechnology in Glioblastoma Multiforme
}

\author{
Talita Glaser"1, Inbo Han², Liquan Wu ${ }^{3 *}$ and Xiang Zeng ${ }^{4 *}$ \\ ${ }^{1}$ Department of Biochemistry, Institute of Chemistry, University of São Paulo, São Paulo, Brazil, ${ }^{2}$ Department of \\ Neurosurgery, Spine Center, CHA University, CHA Bundang Medical Center, Seongnam, South Korea, ${ }^{3}$ Department of \\ Neurosurgery, Renmin Hospital of Wuhan University, Wuhan, China, ${ }^{4}$ Department of Histology and Embryology, Zhongshan \\ School of Medicine, Sun Yat-sen University, Guangzhou, China
}

OPEN ACCESS

Edited by:

Chiara Riganti,

University of Torino, Italy

Reviewed by:

Olivier Micheau,

Institut National de la Santé et de la

Recherché Médicale (INSERM),

France

Stefano Giovagnoli,

University of Perugia, Italy

*Correspondence:

Xiang Zeng

zengx33@mail.sysu.edu.cn

Liquan Wu

wuliquan@whu.edu.cn

Specialty section:

This article was submitted to Pharmacology of Anti-Cancer Drugs,

a section of the journal

Frontiers in Pharmacology

Received: 25 October 2016

Accepted: 14 March 2017

Published: 31 March 2017

Citation:

Glaser T, Han I, Wu L and Zeng X (2017) Targeted Nanotechnology

in Glioblastoma Multiforme.

Front. Pharmacol. 8:166.

doi: 10.3389/fphar.2017.00166
Gliomas, and in particular glioblastoma multiforme, are aggressive brain tumors characterized by a poor prognosis and high rates of recurrence. Current treatment strategies are based on open surgery, chemotherapy (temozolomide) and radiotherapy. However, none of these treatments, alone or in combination, are considered effective in managing this devastating disease, resulting in a median survival time of less than 15 months. The efficiency of chemotherapy is mainly compromised by the blood-brain barrier (BBB) that selectively inhibits drugs from infiltrating into the tumor mass. Cancer stem cells (CSCs), with their unique biology and their resistance to both radio- and chemotherapy, compound tumor aggressiveness and increase the chances of treatment failure. Therefore, more effective targeted therapeutic regimens are urgently required. In this article, some well-recognized biological features and biomarkers of this specific subgroup of tumor cells are profiled and new strategies and technologies in nanomedicine that explicitly target CSCs, after circumventing the BBB, are detailed. Major achievements in the development of nanotherapies, such as organic poly(propylene glycol) and poly(ethylene glycol) or inorganic (iron and gold) nanoparticles that can be conjugated to metal ions, liposomes, dendrimers and polymeric micelles, form the main scope of this summary. Moreover, novel biological strategies focused on manipulating gene expression (small interfering RNA and clustered regularly interspaced short palindromic repeats [CRISPR]/CRISPR associated protein 9 [Cas 9] technologies) for cancer therapy are also analyzed. The aim of this review is to analyze the gap between CSC biology and the development of targeted therapies. A better understanding of CSC properties could result in the development of precise nanotherapies to fulfill unmet clinical needs.

Keywords: cancer stem cell, glioma, nanotechnology, targeted therapy, blood-brain barrier, nanomedicine

\section{INTRODUCTION}

Gliomas, demonstrating glial cell characteristics, represent $30 \%$ of all brain tumors as described by American Cancer Society (2016). These tumors, especially high-grade gliomas and glioblastoma, grow invasively in the central nervous system and cause discernible neurological symptoms within months with an extremely poor prognosis even after aggressive open surgery combined with adjuvant chemo/radiotherapy. New assumptions incriminate cancer stem 
cells (CSCs) as a possible cause of tumor treatment resistance. However, the biological nature of these cells is still undetermined (Louis et al., 2007; Westphal and Lamszus, 2011).

The development of new technologies based on nanometersized particles (nanotechnology) for cancer treatment has been extensively investigated in the last decade and this approach shows potential for glioma diagnosis and treatment. Unique molecular signatures for each type of tumor have been uncovered recently, because of advances in proteomics and genomics, opening new paths for therapies that specifically target and kill tumor cells (Cruceru et al., 2013).

In this review paper, the challenges in targeting gliomas are highlighted. The concept of CSCs and their biomarkers is introduced initially, and finally, developed nanotechnologies, including some clinical trials, are summarized. Moreover, the application of therapies already used in different fields to glioblastoma multiform (GBM) treatment is proposed, focusing on CSC targeting.

\section{CLINICAL CLASSIFICATION AND CURRENT TREATMENT OF GLIOMAS}

Gliomas are brain tumors that resemble normal stromal (glial) cells of the brain, such as astrocytes (astrocytomas), oligodendrocytes (oligodendrogliomas) and ependymal cells (ependymomas). They are a group of oncological diseases for which no cure exists and little progress has been made in order to guarantee a longer life expectancy. Gliomas can diffusely penetrate throughout the brain and are mainly classified according to their morphological resemblance to their respective glial cell types, their cytoarchitecture and their immunohistological marker profile (Louis et al., 2007; Westphal and Lamszus, 2011).

There is also a glioma grading system that distinguishes, astrocytomas, by four World Health Organization (WHO) grades (I, II, III, and IV); and oligodendrogliomas and oligoastrocytomas, by two grades (II and III) (Louis et al., 2007).

The most aggressive and common glioma is glioblastoma (a grade IV astrocytoma). This tumor demonstrates extensive vascular endothelial proliferation, necrosis, high cell density and atypia. It can evolve from a preexisting secondary glioblastoma (low grade astrocytoma), but usually occurs de novo (primary glioblastoma) (Westphal and Lamszus, 2011).

Recently, as described in the 2016 WHO report on the central nervous system (CNS), it has been recommended that glioblastomas be divided into IDH-wildtype, IDH-mutant and Nitric oxide synthase (NOS). IDH-wild type (about $90 \%$ of cases) is regarded as primary or de novo glioblastoma and prevailing in patients over 55 years of age; IDH-mutant (about $10 \%$ of cases), corresponds to secondary glioblastoma that preferentially arises in younger patients (Louis et al., 2007); and NOS is reserved for cases in which a full IDH evaluation cannot be performed (Louis et al., 2016).

In the last two decades, glioblastoma treatment using chemotherapy has undergone some changes, such as replacing the use of some alkylating substances like carmustine (BCNU), nimustine (ACNU), and lomustine (CCNU) with temozolomide (TMZ). The alkylating agent groups that have been mostly prescribed in the clinic are: TMZ (8-Carbamoyl3-methylimidazo (5, 1-d)-1, 2, 3, 5-tetrazin-4(3H)-one) and nitrosoureas (BCNU, ACNU, CCNU - also referred to as CNUs) (Beier et al., 2011).

Temozolomide is rapidly converted into its reactive format, 5-3-(methyl)-1-(triazen-1-yl) imidazole-4-carboxamide, at physiologic $\mathrm{pH}$, causing DNA damage through methylation of the O6-position of guanines, blocking DNA replication and inducing the death of tumor cells (Kaina et al., 1997; Ochs and Kaina, 2000; Roos and Kaina, 2006) or even cell cycle arrest (Hirose et al., 2001).

In contrast, the CNUs alkylate the N3-position of adenine and the N7-position of guanine inducing apoptotic cell death in p53 wildtype cells and necrotic cell death in p53 deficient cells (Fischhaber et al., 1999; Johannessen et al., 2008).

Currently, TMZ, together with radiotherapy and surgical resection, is the most commonly applied glioblastoma treatment. Despite a boost in overall patient survival with TMZ treatment and the low toxicity of TMZ, patient prognosis remains poor. Usually few patients survive longer than 5 years, with a median survival of approximately 14.6 months (Stupp et al., 2005, 2009).

\section{GBM STEM CELLS AND TREATMENT RESISTANCE}

The possible cause of GBM chemoresistance is the presence of CSCs. CSCs are tumor cells with stem cell-like properties that reside in GBM and can readily generate both proliferating progenitor-like and differentiated tumor cells amid microenvironment cues (Morokoff et al., 2015). CSCs could be more resistant towards radio- and chemotherapy and survive intensive oncological therapies, leading to tumor recurrence (Modrek et al., 2014). Since GBM is an aggressive tumor, the development of alternative therapies targeting CSCs is urgently needed.

The origin of CSCs can be either mutated embryonic stem cells or downstream progenitors, that may already exist at birth or accumulate over time through mutation (Shipitsin and Polyak, 2008). Recent studies have revealed that the "de-differentiation" of non-CSCs into CSCs can be an alternative mechanism of CSC creation (Safa et al., 2015), suggesting that diverse cell types, from stem cells to their related differentiated progeny, are amenable to oncogenic transformation.

Distinguishing between CSCs and other tumor populations largely lies in the functional multipotency that stem cells demonstrate, i.e., the self-renewal and differentiation to multiple progeny capabilities. Cells that are tumorigenic and can differentiate hierarchically are commonly regarded as CSCs (termed alternatively as glioma stem cells, glioma CSCs, or brain tumor stem cells). Also, CSCs can form sphere-shaped colonies, however, it is not considered as a default feature (Pastrana et al., 2011). 


\section{BIOMARKERS FOR GLIOMA STEM CELLS}

The CSC hypothesis states that CSCs escape multimodal therapy, causing tumor resistance. Some causes of this resistance could be insufficient drug delivery to CSCs niche or non-specific targeting, since the therapies generally target more differentiated tumor cells. Another premise of this hypothesis is that therapies which efficiently eliminate the CSC fraction of a tumor are able to induce long-term responses and thereby halt tumor progression. The best-described marker for CSCs is CD133, and recently new molecules such as CD15/ stage specific embryonic antigen-1 (SSEA-1) and integrin a6 have been described as novel markers. However, there is not yet a consensus on the optimal markers for CSCs in GBM. CSCs have been isolated from cancer to be analyzed and later used to screen for stem cell-specific biomarkers in tumor cells, particularly surface biomarkers. Cell-surface markers are generally cell membrane-surface antigens to which antitumor drugs can easily bind, consequently increasing the therapeutic efficiency of the drug. Therefore, membrane surface markers are more meaningful than nuclear or cytoplasmic antigens in targeted tumor therapy.

\section{CD133 and its Limitations}

CD133 belongs to the Prominin family, and is also known as Prominin 1, with five transmembrane regions. Singh et al. (Singh et al., 2004) found that 100 CD133 positive cells is enough to induce tumorigenesis in the NOD/SCID mouse brain and whereas 100,000 CD133 negative cells were incapable of tumorigenesis. Subsequently, CD133 has been widely recognized as a biomarker of glioma stem cells.

Although many studies have demonstrated transplanted tumors using CD133+ cells, some researchers have reported on the limitations of CD133 as tumor stem cell marker. CD133+ cells serve as tumor stem cells in many organs, such as brain, lung and colon cancers, but expect for gastric or breast (Su et al., 2015). CD133+ cells only had tumor initiating effects in some glioma cells and were not found in other brain tumors, such as CD15+, CD133- medulloblastomas (Read et al., 2009). Different types of glioblastoma cells derived from different patients can produce CD133+ or CD133- tumor stem cells after serum-free culture in vitro, both of whom embrace stem cell features, tumorigenic characteristics and capability of regenerating CD133+ and CD133 - cell populations. CD133+ glioma stem cells can differentiate into CD133- tumor cells; CD133 - glioma cells injected into nude rats formed tumors containing CD133+ cells (Joo et al., 2008; Wang et al., 2008). Therefore, CD133+ cells are not the only cells with the characteristics of glioma stem cells, and CD133- cells exist as CSCs.

\section{CD44}

Recent studies have demonstrated that some glioma cell subpopulations highly express CD44, a distinctive cell adhesion molecule (Xu et al., 2010). CD44 is a glycoprotein commonly expressed in numerous malignancies (Bradshaw et al., 2016).
CD44 knockdown in GBM xenograft models has inhibited tumor cell growth while improving the response to chemotherapy (Y. Xu et al., 2010). CD44 and CD133 are usually co-expressed in GBM spheres (Brown et al., 2015). Collectively, these data suggest that CD44 may be useful as a CSC marker.

\section{Integrin- $\alpha 6$}

Integrin- $\alpha 6$ is a member of the heterodimer integrin family and is a laminin member of the extracellular matrix protein family. Integrin- $\alpha 6$ can be used as a marker of neural stem cells and the expression of integrin- $\alpha 6$ can be used to detect the tumorigenic potential of normal neural stem cells (Corsini and Martin-Villalba, 2010). Integrin- $\alpha 6$ is highly expressed by the glioma stem cell population and can be used to isolate glioma stem cells (Lathia et al., 2010; Velpula et al., 2012). The function of integrin- $\alpha 6$ lies in self-renewal, proliferation, survival and growth of tumor cells in vitro, and so it can be used as a regulatory target of tumor growth, while its genetic knockout can reduce tumorigenesis (Lathia et al., 2010).

\section{CD15}

Also known as SSEA-1, it is a carbohydrate antigen on the cell surface. Read et al. (Read et al., 2009) found that tumor cells that are CD15+ and CD133 - had the characteristics of tumor stem cells through mouse medulloblastoma experiments. The tumorigenicity of CD15+ cells is 100 times higher than that of CD15- cells in human glioblastoma, where all CD15+ cells were also found to be CD133+, while most CD133+ cells also expressed CD15, suggesting that CD15 is highly likely to be another surface marker of glioblastoma stem cells (Son et al., 2009).

\section{L1CAM}

L1 cell adhesion molecule (L1CAM) belongs to the nerve cell adhesion molecule category and to the type I transmembrane glycoprotein of immunoglobulin super family and is crucial in nervous system development. L1CAM supports the survival and proliferation of CD133+ glioma cells, both in vitro and in vivo, and can be targeted as CSC-specific marker for precise treatment in malignant gliomas (Bao et al., 2008). L1CAM activates some signaling pathways such as fibroblast growth factor receptor (FGFR) and focal adhesion kinase (FAK) through integrin, increasing the growth and motility of GBM cells in autocrine or/and paracrine manner. These effects can be intervened by using small-molecule inhibitors of FGFR, integrins and FAK (Anderson and Galileo, 2016).

\section{CD90}

Also known as Thy-1, CD90 is a member of the cell adhesion molecule immunoglobulin super family. CD90 has been found on the surfaces of nerve cells, thymocytes, fibroblast subsets, endothelial cells, mesangial cells, and hematopoietic stem cells, suggesting that CD90 is a surface marker in hematopoietic stem cells (Kumar et al., 2016), mesenchymal stem cells (Kimura et al., 2016) and hepatocellular stem cells (Yang et al., 2008). CD90 is overexpressed in GBM and is almost absent in low-grade gliomas 
or normal brain tissues. All CD133+ glioma cells expressing CD90, and CD90+/CD133+ and CD90+/CD133- cells have the same self-renewal ability, indicating that $\mathrm{CD} 133+$ glioma stem cells may be a subtype of CD90+ glioma cells (He et al., 2012). In addition, CD90+ cells were also found in glioma peritumoral vessels (Inoue et al., 2016). Therefore, CD90 can be used as a prognostic index of glioma, a marker of glioma stem cells and an indicator of glioma angiogenesis as well.

\section{A2B5}

A2B5 is a ganglioside on the surface of the glial precursor cell membrane. Ogden et al. (Ogden et al., 2008) detected more $\mathrm{A} 2 \mathrm{~B} 5+$ cells than $\mathrm{CD} 133+$ cells in glioblastoma samples, and CD133+ cells were rarely detected. The cells were screened and sorted using flow cytometry, and sequential culture of A2B5+/CD133- and A2B5+/CD133+ cells showed stem cell proliferative activity while that of A2B5-/CD133- cells did not. Tchoghandjian et al. (Tchoghandjian et al., 2010) confirmed that A2B5+/CD133 - and A2B5+/CD133+ cells could form tumor stem cell spheres, while A2B5-/CD133 - cells could not. These studies also show that CD133 - cell populations still contain cells with stem cell activity, and A2B5+ cells may be one type of such stem cells. CD133-/A2B5+ glioma-initiating cells possess a strong migratory and invasive capacity; these cells may be an important subpopulation with high invasive potential in GBM (Sun et al., 2015).

Recently, some typically expressed embryonic stem cells markers have been considered as the markers for tumor-initiating cells, such as c-Myc, SOX2, and OCT-4. These markers could be useful as a tool to identify and isolate CSCs (Ignatova et al., 2002). Moreover, Nestin, OCT-4, NANOG, SOX2, c-Myc, and KLF4 have been described as key players in the transcriptional regulation of glioblastoma CSCs (Ignatova et al., 2002; Yang et al., 2008; Guo et al., 2011; Zhu et al., 2014).

\section{APPLICATION OF NANOTHERAPIES IN GBM}

Besides drug discovery, the delivery of drugs to the brain is a major challenge in treating CNS diseases. Invasive procedures like tumor resection are not always effective for cancer treatment and are extremely complicated and delicate. A possible alternative to overcome this issue is to use systemic delivery; however, the blood-brain barrier (BBB) is an obstacle because of its low permeability, requiring higher doses of drugs, which causes increased side effects. The BBB inhibits the delivery of therapeutic agents to the CNS and prevents a large number of drugs, including antibiotics, antineoplastic agents, and neuropeptides, in passing through the endothelial capillaries to the brain (Fiandaca et al., 2011; Aryal et al., 2014; Pardridge, 2014). Safe disruption or loosening of the BBB is highly important to deliver drugs into brain niches. Successful delivery of drugs can be achieved through $\mathrm{BBB}$ disruption using ultrasound in intraarterial infusion therapy. This allows both chemotherapeutic agents and antibodies to bypass the BBB (Kuittinen et al., 2013). In addition, $\mathrm{K}^{+}(\mathrm{Ca})$ channels have been identified as potential targets for modulation of BBB permeability in brain tumors by assisting the formation of pinocytic vesicles of drugs (Ningaraj et al., 2003). Moreover, tumor drug delivery can be enhanced if they are injected into the brain along with a vasodilator, such as bradykinin, nitric oxide donors or agonists of soluble guanylate cyclase, and calcium dependent potassium $\mathrm{K}^{+}(\mathrm{Ca})$ channels. Furthermore, cerebral blood flow could be modulated and the therapeutic efficacy was augmented after applying a nitric oxide donor which selectively open the blood tumor barrier in rats with intracerebral C6 gliomas (Fross et al., 1991; Weyerbrock et al., 2003, 2011; Black and Ningaraj, 2004).

Aiming to enhance transport through or bypass the $\mathrm{BBB}$, many research groups have been developing new nanotechnologies to overcome these obstacles. Many biochemical modifications of drugs and drug nanocarriers have been developed, enabling local delivery of high doses while avoiding systemic exposure. In this review section, BBB properties and recently discovered nanotechnologies that allow systemic drug delivery for CNS cancer therapy are discussed.

\section{THE BLOOD-BRAIN BARRIER}

The $\mathrm{BBB}$ is a barrier that presents selective permeability carried out by endothelial cells lining the lumen of brain capillaries, which lack pinocytosis and fenestrations because of the presence of tight junction complexes (Eichler et al., 2011; Chacko et al., 2013; Papademetriou and Porter, 2015). In addition to tight junction complexes, the $\mathrm{BBB}$ degrade drugs preventing them to reach the target location due to drug metabolizing enzymes presence, besides the existence of active efflux transporters (AETs) that cargo drugs back to the blood and enzymes that metabolize the drugs before their releasing to the destination. (Regina et al., 2001; Ohtsuki and Terasaki, 2007; Papademetriou and Porter, 2015) (Figure 1). The tight junctions in the $\mathrm{BBB}$ are mainly composed of claudins and occludins (Nitta et al., 2003; Abbott et al., 2010; Haseloff et al., 2014). Claudin 5 is critical for the restriction of small molecules ( $<800$ daltons) and the loss of some claudins, like claudin 3 , is related to the increased BBB permeability in tumor vasculature and autoimmune encephalomyelitis (Wolburg et al., 2003). In contrast, the BBB remains intact in infiltrating gliomas or micrometastatic tumors, indicating that it is crucial to modulate the BBB permeability in these regions.

Transport across the BBB is selective for molecules smaller than $12 \mathrm{~nm}$ and is finely regulated; there are mainly two types of transport, carrier-mediated transport (CMT) and receptormediated transport (RMT) (Papademetriou and Porter, 2015) (Figure 1).

\section{Carrier-Mediated Transport}

The transport of energy production molecules like glucose and lactate, nucleosides, and ions through the cell membrane by facilitated or active transport can be mediated by CMT. In addition, CMT aids the clearance of neurotoxic substances, metabolites of brain function, and neurotransmitters, through 


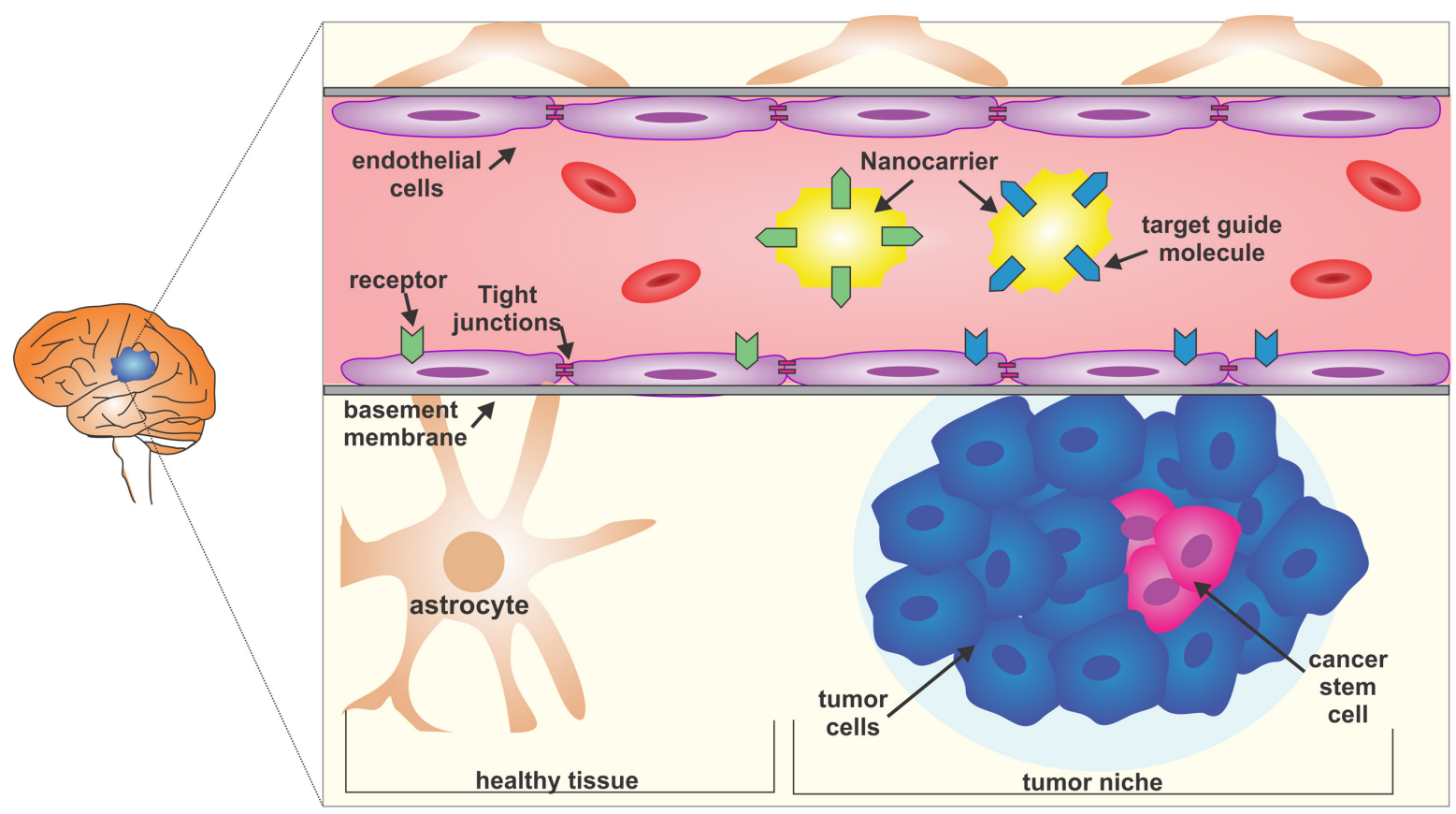

FIGURE 1 | The blood-brain barrier (BBB) and the glioblastoma multiform (GBM) niche. The BBB is selective and restrictive to a variety of molecules. Endothelial cells and the basement membrane, together with strong lateral tight junctions, maintain the selective permeability. A possible strategy to reach the glioma core is to use nanocarriers coupled with target guiding molecules that, for example, bind to the membrane receptors of both tumor niche infiltrated BBB or healthy $\mathrm{BBB}$, and which carry nanomedicines. Glioblastoma is composed of heterogeneous cell populations and the cancer stem cells are responsible for treatment resistance.

AETs (Ohtsuki and Terasaki, 2007; Sanchez-Covarrubias et al., 2014; Papademetriou and Porter, 2015).

The biochemical modification of small molecules enables changes in some parameters like solubility, stability, lipophilicity, and recognition by AETs. Redesign of drug aiming to improve the recognition by $\mathrm{CMT}$ and transportation through $\mathrm{BBB}$ can be achieved by coupling the drug to a regular CMT substrate. The molecular structure of the drug should mimic that of the endogenous CMT substrate (e.g., sugars, amino acids, nucleosides) with pharmacologic activity preserved, but preferably not affect CMT function to avoid possible side effects (Misra et al., 2003; Papademetriou and Porter, 2015).

\section{Receptor-Mediated Transport}

In contrast to CMT, RMT promotes the permeability of some macromolecules into the brain, such as lipoproteins, hormones, nutrients and growth factors (Papademetriou and Porter, 2015). The RMT process is mediated by the binding of the molecule to a cell-surface receptor that presents in endothelial cells on the luminal surface, following endocytosis and transportation of vesicles to the destination, and sequential exocytosis of the vesicle to the extravascular space (Abbott et al., 2010; Georgieva et al., 2014; Papademetriou and Porter, 2015).

The approach targeting RMT requires the involvement of a specific ligand (e.g., an antibody or antibody fragment, synthetic peptide, natural ligand), which has affinity for an endocytic receptor expressed on the endothelial cell surface, to the chemotherapeutic drug or to a drug-loaded nanocarrier. Binding to the targeted receptor induces intracellular signaling cascades mediating invagination and formation of membranebound vesicles in the cell interior, and then intracellular vesicular trafficking transport to the abluminal endothelial plasma membrane (Abbott et al., 2010; Georgieva et al., 2014; Papademetriou and Porter, 2015).

\section{NANOCARRIERS}

The discussion of nanosystems in this review mainly focuses on liposomes, polymeric nanoparticles, solid lipid nanoparticles, polymeric micelles and dendrimers as carriers (Figure 2).

\section{Liposomes}

Lipid-bilayer vesicles, namely liposomes, are popular drug systems for delivery due to their easy preparation, their encapsulation capability of a wide array of drugs, their biocompatibility, efficiency, non-immunogenicity, enhanced solubility of chemotherapeutic agents, and commercial availability. The clearance of liposomes by macrophages is relatively fast, so modifications of the liposome surface or size can extend their circulation time. Specificity for the nervous system is possible by coupling liposomes to aptamers or monoclonal antibodies against transferrin receptors (OX-26), glial fibrillary acidic proteins or the insulin receptor (Kanai et al., 2014). The use of liposomes for gene delivery has been 


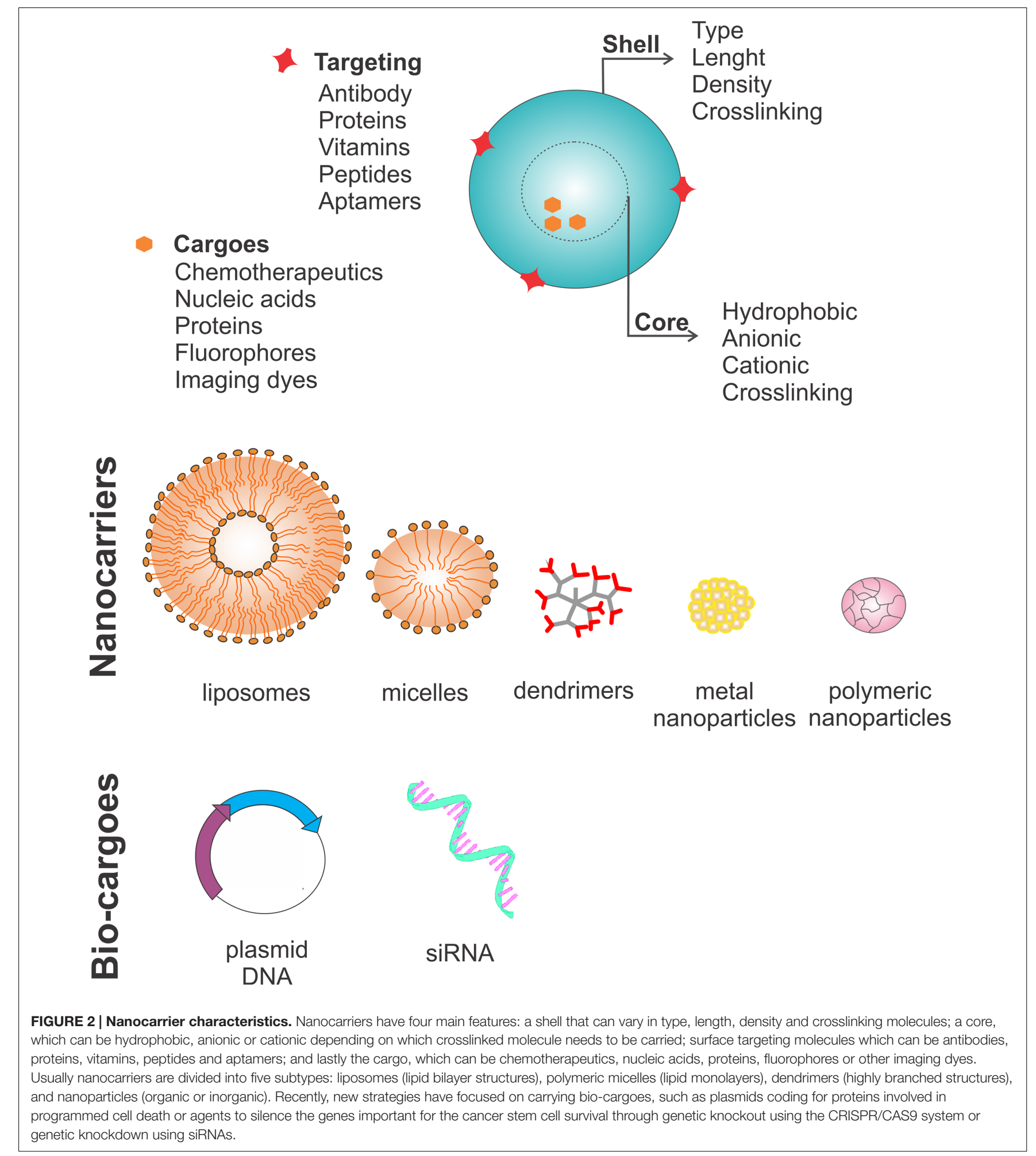

demonstrated by injecting liposomes carrying a plasmid coding for the green fluorescence protein in rats. Also, in tumor therapy, liposomes carrying small interfering RNA (siRNA) have been deployed, while the diesteryl phosphoethanolamine poly carboxybetaine lipid which promotes endosomal/lysosomal escape was developed for systemic delivery of siRNA (Dai et al., 2014; Ozpolat et al., 2014).

Furthermore, trafficking cargo across the BBB is improved when using nanocarriers that target CMT. For example, liposomes targeting glucose transporter 1 (GLUT1) enhanced 
transport of daunorubicin (Ying et al., 2010), while doxorubicin delivery to the brain was 4.8 -fold enhanced after equipped with liposomes that targeted glutathione transporters (2B3-101). This approach is particular suitable for small molecules delivery rather than that of large ones. In another study, 2B3-101 was reported as reaching clinical trials and this will be further detailed along this review (Birngruber et al., 2014; Papademetriou and Porter, 2015).

\section{Nanoparticles (NPs)}

Nanoparticles (NPs) have also been widely studied, because of their high drug-loading capacity and protection against chemical and enzymatic degradation. NPs have enormous medical potential and have emerged as a major tool in nanomedicine, compared with conventional drug delivery methods. NPs are solid colloidal particles made of polymers ranging from 1 to $1000 \mathrm{~nm}$, and are divided in two types, nanospheres and nanocapsules (Couvreur et al., 2002). An interesting application of NPs is the magnetic format of NPs that are made of a magnetic core of iron oxide or magnetite and a biocompatible covering shell of dextran or starch, to be distributed through an organism that is exposed to a localized magnetic field. In vivo GBM models have shown that magnetic NPs are promising. Detailed reviews concerning NP applications have already been published (Laquintana et al., 2009; Upadhyay, 2014).

\section{Polymeric Micelles}

Polymeric micelles range from 10 to $100 \mathrm{~nm}$ and have a coreshell architecture like NPs. They spontaneously self-assemble in aqueous solutions at concentrations higher than a threshold concentration termed the critical micelle concentration. The core is constructed mainly by hydrophobic polymer parts such as poly(caprolactone), poly (propylene glycol) (PPG), or poly(D,Llactide), together with a hydrophilic shell made of poly(ethylene glycol) (PEG). Pluronic micelles (PEG-PPG-PEG) have emerged as good candidates for brain therapy, since they can easily cross the $\mathrm{BBB}$ and inhibit drug efflux. Micelles carrying paclitaxel were able to increase the toxicity of the chemotherapeutic drug in a LN18 human glioblastoma cell line (Liu et al., 2008; Laquintana et al., 2009).

\section{Dendrimers}

Dendrimers are highly branched polymer molecules smaller than $12 \mathrm{~nm}$. Conjugation to dendrimers confers enhanced delivery across the $\mathrm{BBB}$, which in polyether-copolyester dendrimers loaded with methotrexate and D-glucosamine and tested against avascular glioma spheroids resulted in increased methotrexate potency. After a week, dendrimers do not affect the viability of neural cells nor induce local microglia activation even at submicromolar range of concentration. A better understanding of dendrimer distribution patterns may facilitate the design of nanomaterials for future clinical applications (Laquintana et al., 2009).

\section{Metal Particles}

Metal particles have been studied extensively because it has been demonstrated that they enhance the susceptibility of tumor tissues to injury induced by radiation exposure, and are therefore a promising candidate for nanomedicine. Application of gold NPs prior to radiation produced distinctive DNA damage in tumors and improved the survival of tumor bearing animals (Joo et al., 2008; Bobyk et al., 2013). Previous research has suggested that the enhanced radiosensitization effects were led by low-energy electrons emission from gold particles and in a dose-dependent maner (Zheng et al., 2008). Similarly, the radiosensitization effect of silver NPs is also attributed to their interactions with the DNA repair system, which eventually leads to the arrest of DNA duplication and cell apoptosis (Xu et al., 2009). After irradiation, titanium dioxide (TiO2) induces tumor cell death by increasing the production of free radicals. The amount of reactive oxygen species generated is dose-dependent on the amount of $\mathrm{TiO} 2$ applied as a radiosensitizer when the cells are exposed in X-rays (Park et al., 2008).

\section{EMERGING STRATEGIES USING NANOCARRIERS}

\section{Hyperthermia}

Hyperthermic treatment strategies use a magnetic medium such as thermoseeds and magnetic NPs to apply moderate heating in a specific area of the organ where the tumor is located. The combination of carbon nanotubes (CNTs) with near-infrared radiation (NIR) was effective in debulking a tumor in rats, leading to tumor shrinkage without recurrence. Furthermore, this protocol could eliminate glioma CSCs, both drug-sensitive and drug-resistant glioma cells due to the broad-spectrum absorption of CNTs by gliomas. In contrast, normal cells were merely affected, demonstrating the lower uptake of CNTs (Santos et al., 2014). Hyperthermia in glioma treatment remains controversial because it is technically difficult to impose a lethal dose of heat to all cell populations within the glioma mass. The heterogeneous response to different grades of hyperthermia may change the biological nature of the surviving tumor cells. For example, following moderate thermal preconditioning human glioma cell lines demonstrate increased proliferation in vitro and aberrant aggressiveness in a xenograft model. The transient increase in growth of the CD133 subtype of gliomas after thermal preconditioning indicates that there might be a compensation for the loss of the thermal sensitive sub-population (Zeng et al., 2016).

To further increase selectivity for CSCs, antibodies against the CD133 surface marker can be employed as a targeting moiety. Photothermal therapy using single-walled carbon nanotubes (SWNTs) conjugated with anti-CD133 antibodies (CDSWNTs) produced a targeted lysis of CD133+ GBM CSCs, while CD133GBM cells remained intact in vitro. A discernible shrinkage of tumor after subcutaneous NIR laser irradiation following CDSWNT administration in this particular ectopic GBM tumor model (Wang et al., 2011). NIR photoimmunotherapy, employing a monoclonal CD133 antibody (mAb) conjugated to an IR700 phototoxic phthalocyanine dye, permitted a spatiotemporally controlled elimination of tumor cells through 
specific image guidance. Rapid cell death was observed after CD133 mAb intravenous administration followed by harmless NIR light applied through the intact skull. This proof of principle study offers a promising theranostic agent that can be applied in intraoperative imaging or histopathological evaluation to define the tumor borders, as well as eradication of CSCs specifically and efficiently (Jing et al., 2016).

\section{Antitumor Antibiotics}

Antitumor antibiotics are a form of chemotherapeutic that interferes with DNA and slows or stops cancer cells from multiplying. Antitumor antibiotics demonstrate promise in treating gliomas. For example, doxorubicin (trade name: Adriamycin $\left.{ }^{\circledR}\right)$, daunorubicin (trade name: Cerubidine ${ }^{\circledR}$ ), and bleomycin (trade name: Blenoxane ${ }^{\circledR}$ ), show powerful anticancer activity against gliomas cells in vitro. Their efficacy in vivo was reported to be poor, which was largely attributed to their inability to penetrate the BBB (von Holst et al., 1990). However, once these antibiotics are encapsulated in PEGylated liposomes (for example, Doxil ${ }^{\circledR}$ is a PEGylated form of liposomal doxorubicin), the prolonged survival of treated animals is observed following an enhanced local antitumor effect (Sharma et al., 1997). Overall, the antitumor effects of liposomal doxorubicin, daunorubicin, or bleomycin have been unsatisfactory against glioma in patients (Fabel et al., 2001; Fiorillo et al., 2004). Further, to promote the efficacy of liposomal formulations against brain tumors, more effective drug-delivery strategies are clearly in need. For example, the combination of ultrasound-induced microbubbles, which create transient local BBB permeability, with liposomal doxorubicin has been reported to have a significant antitumor effect (Aryal et al., 2013, 2015).

\section{Engineering of Cell Genome}

Recently, the advance of new technologies that facilitate the engineering of the cell genome, like clustered regularly interspaced short palindromic repeats (CRISPR)/Cas 9 and silencing RNA, has provided new methods to deliver nucleic acids to the brain, and in particular for glioma treatment. For this purpose, positively charged and degradable polymers, including chitosan, poly(beta-amino esters), poly(amidoamines), and many other cationic polymers have been used, because of their cationic nature, which allows complexation with negatively charged molecules like DNA or RNA. Inorganic NPs are better applied for imaging and drug delivery purposes, because their synthesis is easily tunable and reproducible (Cardoso et al., 2007; Tzeng and Green, 2013). Some examples are injectable superparamagnetic iron oxide NPs, which are used as contrast agents for magnetic resonance imaging, and gold NPs that are used to carry a conjugated drug. Coated spherical gold NPs carrying a highly oriented layer of siRNA are well protected from nuclease degradation and provide highly efficient knockdown.

Liposomes have also been used to deliver the IFN- $\beta$ gene in mouse models of glioma, resulting in immune response induction and reduced tumor growth. Five malignant glioma patients were treated using liposomes carrying the IFN- $\beta$ gene in a pilot clinical trial and four patients showed $>50 \%$ tumor reduction or stable disease (Yoshida et al., 2004). Moreover, since Apo2L/tumor necrosis factor-related apoptosis inducing ligand (TRAIL) is fairly specific for cancer cells, a TRAIL plasmid encapsulated in PEG-conjugated PLA NPs ( $<120 \mathrm{~nm}$ ) was injected intravenously and caused an increased median survival time (Hawkins, 2004; Lu et al., 2006).

To avoid GBM recurrence, the protein product of the delivered gene should be designed to be active in CSCs. In addition, the construct can be under the control of a cancerspecific promoter, such as survivin or PEG3, to ensure that healthy cells are not transfected or transduced (Su et al., 2005; Van Houdt et al., 2006). The delivery of miRNAs, such as miR124 and miR-137, can induce terminal differentiation and cell death in murine CSCs in vitro (Silber et al., 2008). Moreover, Gangemi et al. used an shRNA-expressing plasmid in a retroviral vector for in vitro knockdown of SOX2, leading to inhibited CSC proliferation, self-renewal, and tumor-initiating capacity (Gangemi et al., 2009).

Recently, modified siRNAs have been developed that are protected from nuclease degradation and can be readily taken up into cells. This type of modification allows researchers to focus on developing engineered NPs with a prolonged circulation time and site-specific delivery, instead of siRNA protection, thus accelerating clinical translation.

\section{CLINICAL TRIALS}

Few clinical trials using nanotherapies to target GBM have been conducted; this review focuses on glioma treatment, and the information about these clinical trials is summarized in Table $\mathbf{1}$.

Ang-1005 (also named GRN-1005) was designed to circumvent $\mathrm{BBB}$ under several clinical trials. Ang-1005 is conjugated to paclitaxel and to the RMT ligand angiopep-2 that targets LRP1. In a phase I trial, the drug tolerance of maximum dose of $650 \mathrm{mg} / \mathrm{m}^{2}$ was shown. A pharmacokinetics and tumor resections analysis proved that Ang-1005 kept intact in blood plasma so as to remain sufficient concentrations for cytotoxicity when approaching tumor samples (Thomas et al., 2009; Papademetriou and Porter, 2015; Regina et al., 2015).

To the best of our knowledge, nanocarrier-based RMTtargeting strategies in GBM treatment have very limit clinical trial outcomes. It has been described that PEGylated liposomal doxorubicin without RMT-targeting was evaluated in phase I studies in GBM patients, showing no improvements in progression nor survival (Papademetriou and Porter, 2015). In Phase I/II clinical trials, solid tumors and metastatic brain cancer or malignant recurrent glioma patients were treated with 2B3-101 encapsulated by a PEGylated liposomal doxorubicin nanocarrier employing glutathione to target glutathione transporters (CMT-based targeting) (Birngruber et al., 2014).

SGT-53 is a nanocarrier composed of cationic liposomes that encapsulate a plasmid for the p53 tumor suppressor, and which displays scFv-targeting TfR. One phase II clinical trial of SGT-53 is to combine it with TMZ for patients with recurrent malignant gliomas, aiming to evaluate tumor cells death after accumulation 

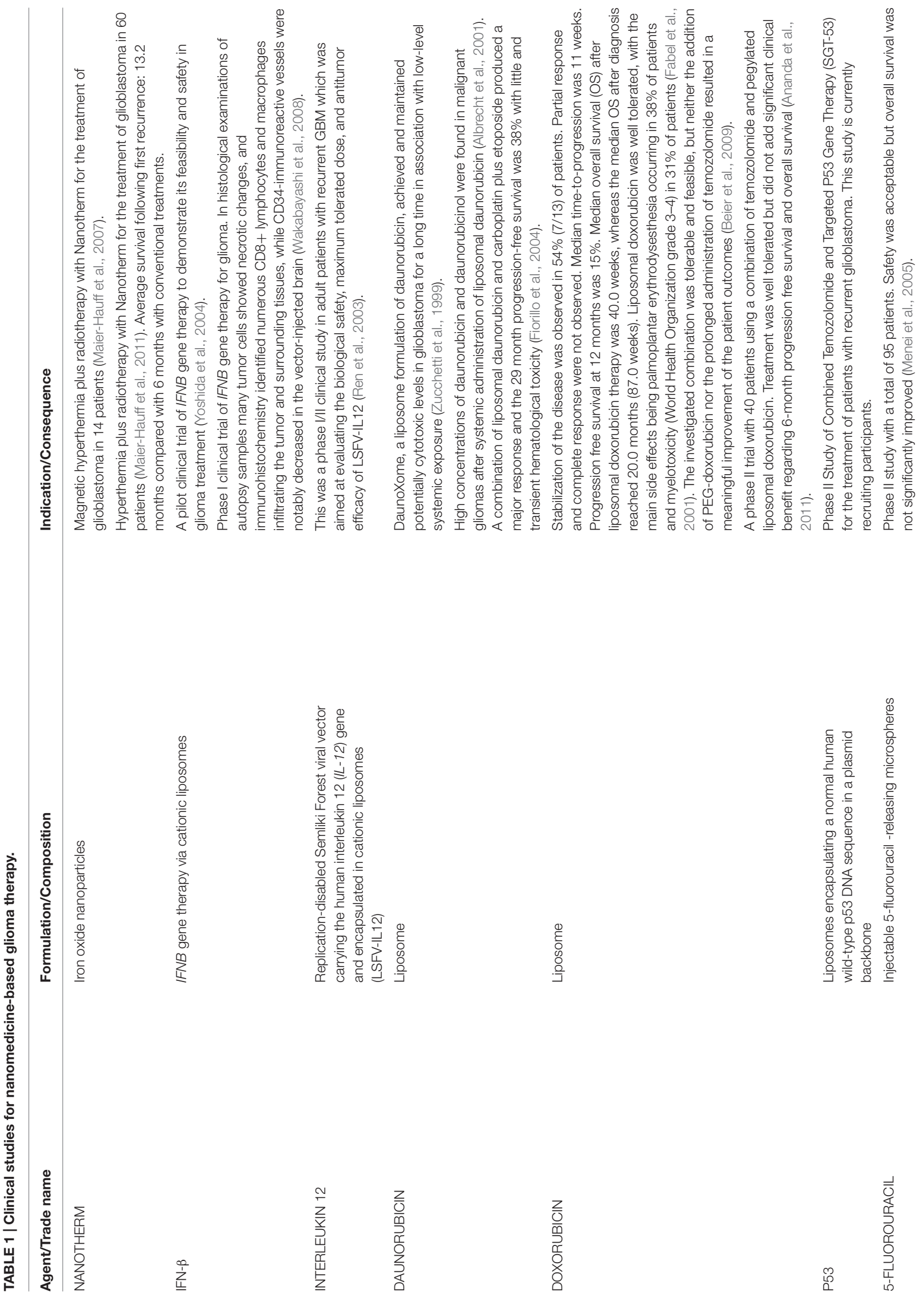

zo
$\frac{0}{M}$
$\stackrel{0}{0}$
0
o
0

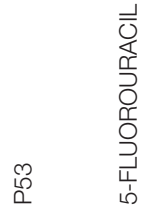



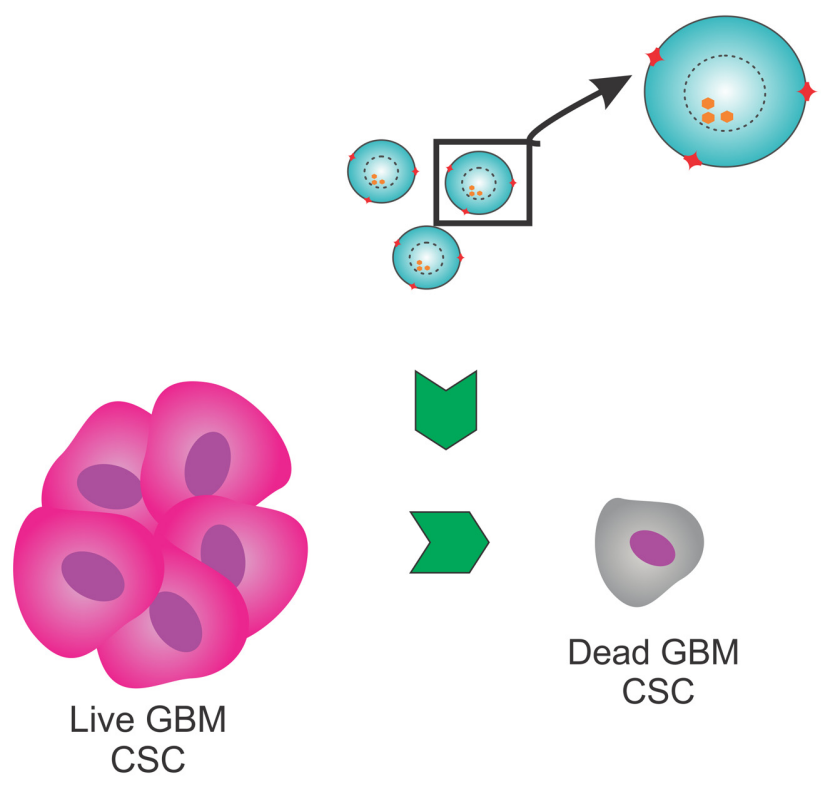

Dead GBM CSC
Nanocarriers

Liposomes

Gold nanoparticles

Targeting molecules

\section{Recognition \\ Antibodies
Aptamers \\ Antibodies
Aptamers}

a Cancer Stem Cell

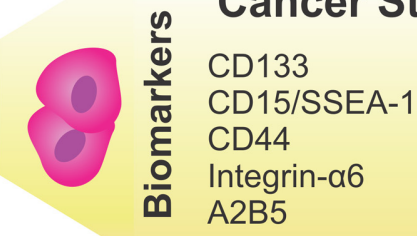

Cargoes

siRNA/ proliferation genes

(SOX-2)

CRISPR/CAS9/ cell death genes

(TRAIL, miR-124 and miR-137,IFN- $\beta$ )

Chemotherapeutics (doxorubicin)

FIGURE 3 | Proposed strategy. This proposed therapeutic strategy targeting the GBM cancer stem cells (CSCs) as a novel treatment, would use liposomes as nanocarriers, because they can shield and carry molecules of different sizes and charges. Liposomes, with a shell coated using aptamers or antibodies specific to CSC markers, such as CD133, CD15, CD44, integrin- $\alpha 6$, or A2B5, would carry antitumor antibiotics (doxorubicin) or genome editing tools such as SOX2, TRAIL, miR-124, miR-137, and IFN- $\beta$, to modulate tumor survival/death gene expression. Alternatively, the use of gold nanoparticles targeting brain markers, like glial fibrillary acidic protein, is recommended to bypass the BBB and deliver genome editing tools.

of the drugs, anti-tumor efficacy, safety and overall survival (Yu et al., 2004; Senzer et al., 2013).

Some trials are now using gene-silencing therapies, including siRNA coupled to D3 and D5 polylysine dendrimers and melittingrafted HPMA oligolysine-based copolymers, for intravenous, intracerebroventricular, or intranasal administration to the CNS. A nanoliposomal formulation of irinotecan (CPT-11) is also in phase I trials for glioma (Krauze et al., 2007).

Moreover, magnetically induced hyperthermia, which uses a magnetic medium such as thermoseeds and magnetic NPs to produce moderate heating in a specific area of the organ where the tumor is located, is under investigation for malignant glioma, prostatic cancer, metastatic bone tumors and some other malignant tumors. Thermoseed magnetic induction of hyperthermia for the treatment of brain tumors was first reported by Kida et al. in 1990. A Fe-Pt alloy thermoseed with a length of $15-20 \mathrm{~mm}$, a diameter of $1.8 \mathrm{~mm}$ and a Curie point of $68-69^{\circ} \mathrm{C}$ was used for seven cases of metastatic brain tumor two to three times a week, with the tumor tissues reaching $44-46^{\circ} \mathrm{C}$ during the treatment. This resulted in two cases of complete response and one case of partial response. Kobayashi et al. (1991) used a thermoseed with a Curie point of $68^{\circ} \mathrm{C}$ for the treatment of 23 patients with brain tumors, and reported an overall response rate of 34.8\% (O’Reilly and Hynynen, 2012; Luo et al., 2014).

PLA is a biodegradable and hydrophobic polymer that can be used as a carrier for hydrophobic chemical drugs for anti-tumor research. Monomethoxy poly(ethylene glycol)-blockpoly(D, L-lactide) loaded with paclitaxel to form Genexol ${ }^{\circledR}$ PM has been trialed clinically and is now commercially available for the treatment of breast cancer, ovarian cancer, and non-small cell lung cancer (Kim et al., 2007; Lee et al., 2008). Jun Chen et al. used PEG-PLA as a paclitaxel delivery carrier. The NPs were coupled with the tLyp-1 peptide, which has a high affinity for neuropilin to target both glioma cells and endothelial cells. The tLyp-1-conjugated NPs showed greater penetration in C6 glioma spheroids and enhanced drug access into solid tumors and prolonged survival time to 37 days in intracranial C6 glioma mice, compared with approximately 20 days in controls. However, smart structural design and modification are required for the proper degradation rate of these bioactive materials ( $\mathrm{Hu}$ et al., 2013). 


\section{CONCLUSION}

In summary, elucidating the biological nature of CSCs offers a new strategy for targeted cancer therapy. Interdisciplinary efforts to develop new nanocarriers that can bypass the BBB, protect the drug from being degraded, and that are specific for tumor cells or CSCs are ongoing. Some groups prefer to focus on developing new drugs that can efficiently kill CSCs, which are responsible for treatment resistance and a poor prognosis in glioblastoma, while some research groups are using modern and pioneering molecular biology tools, such as CRISPR/Cas 9 and siRNA.

To develop a novel treatment based on targeting CSCs, an effective strategy should use liposomes as nanocarriers, because of their ability to shield and carry molecules of different sizes and charges. These liposomes should have a shell coated with aptamers or antibodies specific for CSC markers such as CD133, and would carry antitumor antibiotics (doxorubicin) or genome editing tools that would modulate the expression of genes important for tumor survival, such as SOX-2. Another possibility is the use of gold NPs targeting brain markers, such as glial fibrillary acidic protein, to facilitate brain penetration, and deliver

\section{REFERENCES}

Abbott, N. J., Patabendige, A. A., Dolman, D. E., Yusof, S. R., and Begley, D. J. (2010). Structure and function of the blood-brain barrier. Neurobiol. Dis. 37, 13-25. doi: 10.1016/j.nbd.2009.07.030

Albrecht, K. W., De Witt Hamer, P. C., Leenstra, S., Bakker, P. J., Beijnen, J. H., Troost, D., et al. (2001). High concentration of Daunorubicin and Daunorubicinol in human malignant astrocytomas after systemic administration of liposomal Daunorubicin. J. Neurooncol. 53, 267-271. doi: 10.1023/A:1012287212388

American Cancer Society (2016). Cancer Statistics Center. Available at: https:// cancerstatisticscenter.cancer.org/?_ga=1.14923958.1099926323.1483312995\#/ (accessed October 2016).

Ananda, S., Nowak, A. K., Cher, L., Dowling, A., Brown, C., Simes, J., et al. (2011). Phase 2 trial of temozolomide and pegylated liposomal doxorubicin in the treatment of patients with glioblastoma multiforme following concurrent radiotherapy and chemotherapy. J. Clin. Neurosci. 18, 1444-1448. doi: 10.1016/ j.jocn.2011.02.026

Anderson, H. J., and Galileo, D. S. (2016). Small-molecule inhibitors of FGFR, integrins and FAK selectively decrease L1CAM-stimulated glioblastoma cell motility and proliferation. Cell Oncol. 39, 229-242. doi: 10.1007/s13402-0160267-710.1007/s13402-016-0267-7

Aryal, M., Arvanitis, C. D., Alexander, P. M., and McDannold, N. (2014). Ultrasound-mediated blood-brain barrier disruption for targeted drug delivery in the central nervous system. Adv. Drug Deliv. Rev. 72, 94-109. doi: 10.1016/j. addr.2014.01.008

Aryal, M., Park, J., Vykhodtseva, N., Zhang, Y. Z., and McDannold, N. (2015). Enhancement in blood-tumor barrier permeability and delivery of liposomal doxorubicin using focused ultrasound and microbubbles: evaluation during tumor progression in a rat glioma model. Phys. Med. Biol. 60, 2511-2527. doi: 10.1088/0031-9155/60/6/2511

Aryal, M., Vykhodtseva, N., Zhang, Y. Z., Park, J., and McDannold, N. (2013). Multiple treatments with liposomal doxorubicin and ultrasound-induced disruption of blood-tumor and blood-brain barriers improve outcomes in a rat glioma model. J. Control. Release 169, 103-111. doi: 10.1016/j.jconrel.2013.04. 007S0168-3659(13)00214-9

Bao, S., Wu, Q., Li, Z., Sathornsumetee, S., Wang, H., McLendon, R. E., et al. (2008). Targeting cancer stem cells through L1CAM suppresses
siRNA to knockdown tumor survival and proliferation genes (Figure 3).

Finally, some clinical trials have succeeded in testing new nanotechnologies that may become available to patients in the near future.

\section{AUTHOR CONTRIBUTIONS}

TG, IH, LW, and XZ summarized the literature and drafted the manuscript. TG, XZ, and LW revised and edited the manuscript. $\mathrm{XZ}$ and LW supervised the work. TG and XZ initiated, finalized, and submitted the manuscript.

\section{FUNDING}

We thank the following funding sources: Youth Program of National Natural Science Foundation of China (31600780) to XZ. São Paulo Research Foundation (FAPESP) Postdoctoral Fellowship 2015/13345-1 and 2016/07659-6 to TG. National Research Foundation of Korea (NRF) (NRF2014R1A1A2059118) to IH.

glioma growth. Cancer Res. 68, 6043-6048. doi: 10.1158/0008-5472.CAN08-1079

Beier, C. P., Schmid, C., Gorlia, T., Kleinletzenberger, C., Beier, D., Grauer, O., et al. (2009). RNOP-09: pegylated liposomal doxorubicine and prolonged temozolomide in addition to radiotherapy in newly diagnosed glioblastoma-a phase II study. BMC Cancer 9:308. doi: 10.1186/1471-24079-308

Beier, D., Schulz, J. B., and Beier, C. P. (2011). Chemoresistance of glioblastoma cancer stem cells-much more complex than expected. Mol. Cancer 10:128. doi: 10.1186/1476-4598-10-128

Birngruber, T., Raml, R., Gladdines, W., Gatschelhofer, C., Gander, E., Ghosh, A., et al. (2014). Enhanced doxorubicin delivery to the brain administered through glutathione PEGylated liposomal doxorubicin (2B3-101) as compared with generic Caelyx,((R))/Doxil((R))-a cerebral open flow microperfusion pilot study. J. Pharm. Sci. 103, 1945-1948. doi: 10.1002/jps.23994S0022-3549(15) 30507-4

Black, K. L., and Ningaraj, N. S. (2004). Modulation of brain tumor capillaries for enhanced drug delivery selectively to brain tumor. Cancer Control 11, 165-173.

Bobyk, L., Edouard, M., Deman, P., Vautrin, M., Pernet-Gallay, K., Delaroche, J., et al. (2013). Photoactivation of gold nanoparticles for glioma treatment. Nanomedicine 9, 1089-1097. doi: 10.1016/j.nano.2013.04.007

Bradshaw, A., Wickremsekera, A., Tan, S. T., Peng, L., Davis, P. F., and Itinteang, T. (2016). Cancer Stem cell hierarchy in glioblastoma multiforme. Front. Surg. 3:21. doi: 10.3389/fsurg.2016.00021

Brown, D. V., Daniel, P. M. D., Abaco, G. M., Gogos, A., Ng, W., Morokoff, A. P., et al. (2015). Coexpression analysis of CD133 and CD44 identifies proneural and mesenchymal subtypes of glioblastoma multiforme. Oncotarget 6, 6267-6280. doi: 10.18632/oncotarget.3365

Cardoso, A. L., Simoes, S., de Almeida, L. P., Pelisek, J., Culmsee, C., Wagner, E., et al. (2007). siRNA delivery by a transferrin-associated lipid-based vector: a non-viral strategy to mediate gene silencing. J. Gene Med. 9, 170-183. doi: 10.1002/jgm.1006

Chacko, A. M., Li, C., Pryma, D. A., Brem, S., Coukos, G., and Muzykantov, V. (2013). Targeted delivery of antibody-based therapeutic and imaging agents to CNS tumors: crossing the blood-brain barrier divide. Expert Opin. Drug Deliv. 10, 907-926. doi: 10.1517/17425247.2013.808184

Corsini, N. S., and Martin-Villalba, A. (2010). Integrin alpha 6: anchors away for glioma stem cells. Cell Stem Cell 6, 403-404. doi: 10.1016/j.stem.2010.04.003 
Couvreur, P., Barratt, G., Fattal, E., Legrand, P., and Vauthier, C. (2002). Nanocapsule technology: a review. Crit. Rev. Ther. Drug Carrier Syst. 19, 99-134. doi: 10.1615/CritRevTherDrugCarrierSyst.v19.i2.10

Cruceru, M. L., Neagu, M., Demoulin, J. B., and Constantinescu, S. N. (2013). Therapy targets in glioblastoma and cancer stem cells: lessons from haematopoietic neoplasms. J. Cell Mol. Med. 17, 1218-1235. doi: 10.1111/jcmm. 12122

Dai, Z., Arevalo, M. T., Li, J., and Zeng, M. (2014). Addition of poly (propylene glycol) to multiblock copolymer to optimize siRNA delivery. Bioengineered 5, 30-37. doi: 10.4161/bioe.27339

Eichler, A. F., Chung, E., Kodack, D. P., Loeffler, J. S., Fukumura, D., and Jain, R. K. (2011). The biology of brain metastases-translation to new therapies. Nat. Rev. Clin. Oncol. 8, 344-356. doi: 10.1038/nrclinonc.2011.58

Fabel, K., Dietrich, J., Hau, P., Wismeth, C., Winner, B., Przywara, S., et al. (2001). Long-term stabilization in patients with malignant glioma after treatment with liposomal doxorubicin. Cancer 92, 1936-1942. doi: 10.1002/ 1097-0142(20011001)92:7<1936::AID-CNCR1712>3.0.CO;2-H

Fiandaca, M. S., Berger, M. S., and Bankiewicz, K. S. (2011). The use of convectionenhanced delivery with liposomal toxins in neurooncology. Toxins 3, 369-397. doi: 10.3390/toxins3040369toxins-03-00369

Fiorillo, A., Maggi, G., Greco, N., Migliorati, R., D’Amico, A., De Caro, M. D., et al. (2004). Second-line chemotherapy with the association of liposomal daunorubicin, carboplatin and etoposide in children with recurrent malignant brain tumors. J. Neurooncol. 66, 179-185. doi: 10.1023/B:NEON.0000013471. 53015.52

Fischhaber, P. L., Gall, A. S., Duncan, J. A., and Hopkins, P. B. (1999). Direct demonstration in synthetic oligonucleotides that N,N'-bis(2-chloroethyl)nitrosourea cross links $\mathrm{N} 1$ of deoxyguanosine to $\mathrm{N} 3$ of deoxycytidine on opposite strands of duplex DNA. Cancer Res. 59, 4363-4368.

Fross, R. D., Warnke, P. C., and Groothuis, D. R. (1991). Blood flow and blood-totissue transport in 9L gliosarcomas: the role of the brain tumor model in drug delivery research. J. Neurooncol. 11, 185-197. doi: 10.1007/BF00165526

Gangemi, R. M., Griffero, F., Marubbi, D., Perera, M., Capra, M. C., Malatesta, P., et al. (2009). SOX2 silencing in glioblastoma tumor-initiating cells causes stop of proliferation and loss of tumorigenicity. Stem Cells 27, 40-48. doi: 10.1634/ stemcells.2008-0493

Georgieva, J. V., Hoekstra, D., and Zuhorn, I. S. (2014). Smuggling drugs into the brain: an overview of ligands targeting transcytosis for drug delivery across the blood-brain barrier. Pharmaceutics 6, 557-583. doi: 10.3390/ pharmaceutics 6040557

Guo, Y., Liu, S., Wang, P., Zhao, S., Wang, F., Bing, L., et al. (2011). Expression profile of embryonic stem cell-associated genes Oct4, Sox2 and nanog in human gliomas. Histopathology 59, 763-775. doi: 10.1111/j.1365-2559.2011. 03993.x

Haseloff, R. F., Dithmer, S., Winkler, L., Wolburg, H., and Blasig, I. E. (2014). Transmembrane proteins of the tight junctions at the blood-brain barrier: structural and functional aspects. Semin. Cell Dev. Biol. 38, 16-25. doi: 10.1016/ j.semcdb.2014.11.004

Hawkins, C. J. (2004). TRAIL and malignant glioma. Vitam. Horm. 67, 427-452. doi: 10.1016/S0083-6729(04)67022-1S0083672904670221

He, J., Liu, Y., Zhu, T., Zhu, J., Dimeco, F., Vescovi, A. L., et al. (2012). CD90 is identified as a candidate marker for cancer stem cells in primary highgrade gliomas using tissue microarrays. Mol. Cell. Proteomics 11, M111010744. doi: $10.1074 / \mathrm{mcp} . M 111.010744$

Hirose, Y., Berger, M. S., and Pieper, R. O. (2001). p53 effects both the duration of $\mathrm{G} 2 / \mathrm{M}$ arrest and the fate of temozolomide-treated human glioblastoma cells. Cancer Res. 61, 1957-1963.

Hu, Q., Gao, X., Gu, G., Kang, T., Tu, Y., Liu, Z., et al. (2013). Glioma therapy using tumor homing and penetrating peptide-functionalized PEG-PLA nanoparticles loaded with paclitaxel. Biomaterials 34, 5640-5650. doi: 10.1016/j.biomaterials. 2013.04.025

Ignatova, T. N., Kukekov, V. G., Laywell, E. D., Suslov, O. N., Vrionis, F. D., and Steindler, D. A. (2002). Human cortical glial tumors contain neural stem-like cells expressing astroglial and neuronal markers in vitro. Glia 39, 193-206. doi: $10.1002 /$ glia. 10094

Inoue, A., Tanaka, J., Takahashi, H., Kohno, S., Ohue, S., Umakoshi, A., et al. (2016). Blood vessels expressing CD90 in human and rat brain tumors. Neuropathology 36, 168-180. doi: 10.1111/neup.12244
Jing, H., Weidensteiner, C., Reichardt, W., Gaedicke, S., Zhu, X., Grosu, A. L., et al. (2016). Imaging and selective elimination of glioblastoma stem cells with theranostic near-infrared-labeled CD133-specific antibodies. Theranostics 6, 862-874. doi: 10.7150/thno.12890thnov06p0862

Johannessen, T. C., Bjerkvig, R., and Tysnes, B. B. (2008). DNA repair and cancer stem-like cells-potential partners in glioma drug resistance? Cancer Treat Rev. 34, 558-567. doi: 10.1016/j.ctrv.2008.03.125

Joo, K. M., Kim, S. Y., Jin, X., Song, S. Y., Kong, D. S., Lee, J. I., et al. (2008). Clinical and biological implications of CD133-positive and CD133-negative cells in glioblastomas. Lab. Invest. 88, 808-815. doi: 10.1038/labinvest. 2008.57

Kaina, B., Ziouta, A., Ochs, K., and Coquerelle, T. (1997). Chromosomal instability, reproductive cell death and apoptosis induced by O6-methylguanine in Mex-, Mex+ and methylation-tolerant mismatch repair compromised cells: facts and models. Mutat. Res. 381, 227-241. doi: 10.1016/S0027-5107(97) 00187-5

Kanai, Y., Wang, D., and Hirokawa, N. (2014). KIF13B enhances the endocytosis of LRP1 by recruiting LRP1 to caveolae. J. Cell Biol. 204, 395-408. doi: 10.1083/ jcb.201309066

Kim, D. W., Kim, S. Y., Kim, H. K., Kim, S. W., Shin, S. W., Kim, J. S., et al. (2007). Multicenter phase II trial of genexol-PM, a novel cremophor-free, polymeric micelle formulation of paclitaxel, with cisplatin in patients with advanced non-small-cell lung cancer. Ann. Oncol. 18, 2009-2014. doi: 10.1093/annonc/ $\operatorname{mdm} 374$

Kimura, K., Kishida, T., Wakao, J., Tanaka, T., Higashi, M., Fumino, S., et al. (2016). Tumor-homing effect of human mesenchymal stem cells in a THMYCN mouse model of neuroblastoma. J. Pediatr. Surg. 51, 2068-2073. doi: 10.1016/j.jpedsurg.2016.09.041

Kobayashi, T., Kida, Y., Tanaka, T., Hattori, K., Matsui, M., and Amemiya, Y. (1991). Interstitial hyperthermia of malignant brain tumors by implant heating system: clinical experience. J. Neurooncol. 10, 153-163. doi: 10.1007/ BF00146877

Krauze, M. T., Noble, C. O., Kawaguchi, T., Drummond, D., Kirpotin, D. B., Yamashita, Y., et al. (2007). Convection-enhanced delivery of nanoliposomal CPT-11 (Irinotecan) and PEGylated liposomal doxorubicin (Doxil) in rodent intracranial brain tumor xenografts. Neuro Oncol. 9, 393-403. doi: 10.1215/ 15228517-2007-019

Kuittinen, O., Siniluoto, T., Isokangas, M., Turpeenniemi-Hujanen, T., Peltonen, J., Alahuhta, S., et al. (2013). Chemotherapy in conjunction with blood brain barrier disruption in the treatment of primary central nervous system lymphoma. Duodecim 129, 1563-1570.

Kumar, A., Bhanja, A., Bhattacharyya, J., and Jaganathan, B. G. (2016). Multiple Roles of CD90 in Cancer. Tumour Biol. 37, 11611-11622. doi: 10.1007/s13277016-5112-010.1007/s13277-016-5112-0

Laquintana, V., Trapani, A., Denora, N., Wang, F., Gallo, J. M., and Trapani, G. (2009). New strategies to deliver anticancer drugs to brain tumors. Expert Opin. Drug Deliv. 6, 1017-1032. doi: 10.1517/17425240903167942

Lathia, J. D., Gallagher, J., Heddleston, J. M., Wang, J., Eyler, C. E., Macswords, J., et al. (2010). Integrin alpha 6 regulates glioblastoma stem cells. Cell Stem Cell 6, 421-432. doi: 10.1016/j.stem.2010.02.018

Lee, K. S., Chung, H. C., Im, S. A., Park, Y. H., Kim, C. S., Kim, S. B., et al. (2008). "Multicenter phase II trial of genexol-PM, a cremophor-free, polymeric micelle formulation of paclitaxel, in patients with metastatic breast cancer. Breast Cancer Res. Treat. 108, 241-250. doi: 10.1007/s10549-007-9591-y

Liu, L., Venkatraman, S. S., Yang, Y. Y., Guo, K., Lu, J., He, B., et al. (2008). Polymeric micelles anchored with TAT for delivery of antibiotics across the blood-brain barrier. Biopolymers 90, 617-623. doi: 10.1002/bip.20998

Louis, D. N., Ohgaki, H., Wiestler, O. D., Cavenee, W. K., Burger, P. C., Jouvet, A., et al. (2007). The 2007 WHO classification of tumours of the central nervous system. Acta Neuropathol. 114, 97-109. doi: 10.1007/s00401-007-0243-4

Louis, D. N., Perry, A., Reifenberger, G., von Deimling, A., Figarella-Branger, D., Cavenee, W. K., et al. (2016). The 2016 world health organization classification of tumors of the central nervous system: a summary. Acta Neuropathol. 131, 803-820. doi: 10.1007/s00401-016-1545-110.1007/s00401-016-1545-1

Lu, W., Sun, Q., Wan, J., She, Z., and Jiang, X. G. (2006). Cationic albuminconjugated pegylated nanoparticles allow gene delivery into brain tumors via intravenous administration. Cancer Res. 66, 11878-11887. doi: 10.1158/00085472.CAN-06-2354 
Luo, S., Wang, L. F., Ding, W. J., Wang, H., Zhou, J. M., Jin, H. K., et al. (2014). Clinical trials of magnetic induction hyperthermia for treatment of tumours. OA Cancer 2, 1-6.

Maier-Hauff, K., Rothe, R., Scholz, R., Gneveckow, U., Wust, P., Thiesen, B., et al. (2007). Intracranial thermotherapy using magnetic nanoparticles combined with external beam radiotherapy: results of a feasibility study on patients with glioblastoma multiforme. J. Neurooncol. 81, 53-60. doi: 10.1007/s11060-0069195-0

Maier-Hauff, K., Ulrich, F., Nestler, D., Niehoff, H., Wust, P., Thiesen, B., et al. (2011). Efficacy and safety of intratumoral thermotherapy using magnetic iron-oxide nanoparticles combined with external beam radiotherapy on patients with recurrent glioblastoma multiforme. J. Neurooncol. 103, 317-324. doi: 10.1007/s11060-010-0389-0

Menei, P., Capelle, L., Guyotat, J., Fuentes, S., Assaker, R., Bataille, B., et al. (2005). Local and sustained delivery of 5 -fluorouracil from biodegradable microspheres for the radiosensitization of malignant glioma: a randomized phase II trial. Neurosurgery 56, 242-248; discussion 242-248. doi: 10.1227/01. neu.0000144982.82068.a2

Misra, A., Ganesh, S., Shahiwala, A., and Shah, S. P. (2003). Drug delivery to the central nervous system: a review. J. Pharm. Pharm. Sci. 6, 252-273.

Modrek, A. S., Bayin, N. S., and Placantonakis, D. G. (2014). Brain stem cells as the cell of origin in glioma. World J. Stem Cells 6, 43-52. doi: 10.4252/wjsc.v6. i1.43

Morokoff, A., Ng, W., Gogos, A., and Kaye, A. H. (2015). Molecular subtypes, stem cells and heterogeneity: implications for personalised therapy in glioma. J. Clin. Neurosci. 22, 1219-1226. doi: 10.1016/j.jocn.2015.02.008

Ningaraj, N. S., Rao, M., and Black, K. L. (2003). Calcium-dependent potassium channels as a target protein for modulation of the blood-brain tumor barrier. Drug News Perspect. 16, 291-298. doi: 10.1358/dnp.2003.16.5.878815

Nitta, T., Hata, M., Gotoh, S., Seo, Y., Sasaki, H., Hashimoto, N., et al. (2003). Sizeselective loosening of the blood-brain barrier in claudin-5-deficient mice. J. Cell Biol. 161, 653-660. doi: 10.1083/jcb.200302070jcb.200302070

Ochs, K., and Kaina, B. (2000). Apoptosis induced by DNA damage O6methylguanine is Bcl-2 and Caspase-9/3 regulated and Fas/caspase-8 independent. Cancer Res. 60, 5815-5824.

Ogden, A. T., Waziri, A. E., Lochhead, R. A., Fusco, D., Lopez, K., Ellis, J. A., et al. (2008). Identification of A2B5+CD133 - tumor-initiating cells in adult human gliomas. Neurosurgery 62, 505. doi: 10.1227/01.neu.0000316019.28421. 9500006123-200802000-00033

Ohtsuki, S., and Terasaki, T. (2007). Contribution of carrier-mediated transport systems to the blood-brain barrier as a supporting and protecting interface for the brain; importance for CNS drug discovery and development. Pharm. Res. 24, 1745-1758. doi: 10.1007/s11095-007-9374-5

O'Reilly, M. A., and Hynynen, K. (2012). Ultrasound enhanced drug delivery to the brain and central nervous system. Int. J. Hyperthermia 28, 386-396. doi: 10.3109/02656736.2012.666709

Ozpolat, B., Sood, A. K., and Lopez-Berestein, G. (2014). Liposomal siRNA nanocarriers for cancer therapy. Adv. Drug Deliv. Rev. 66, 110-116. doi: 10. 1016/j.addr.2013.12.008

Papademetriou, I. T., and Porter, T. (2015). Promising approaches to circumvent the blood-brain barrier: progress, pitfalls and clinical prospects in brain cancer. Ther. Deliv. 6, 989-1016. doi: 10.4155/tde.15.48

Pardridge, W. M. (2014). Targeted delivery of protein and gene medicines through the blood-brain barrier. Clin. Pharmacol. Ther. 97, 347-361. doi: 10.1002/ cpt. 18

Park, E. J., Yi, J., Chung, K. H., Ryu, D. Y., Choi, J., and Park, K. (2008), Oxidative stress and apoptosis induced by titanium dioxide nanoparticles in cultured BEAS-2B cells. Toxicol. Lett. 180, 222-229. doi: 10.1016/j.toxlet.2008. 06.869

Pastrana, E., Silva-Vargas, V., and Doetsch, F. (2011). Eyes wide open: a critical review of sphere-formation as an assay for stem cells. Cell Stem Cell 8, 486-498. doi: $10.1016 /$ j.stem.2011.04.007

Read, T. A., Fogarty, M. P., Markant, S. L., McLendon, R. E., Wei, Z., Ellison, D. W., et al. (2009). Identification of CD15 as a marker for tumor-propagating cells in a mouse model of medulloblastoma. Cancer Cell 15, 135-147. doi: 10.1016/j.ccr.2008.12.016
Regina, A., Demeule, M., Laplante, A., Jodoin, J., Dagenais, C., Berthelet, F., et al. (2001). Multidrug resistance in brain tumors: roles of the blood-brain barrier. Cancer Metastasis Rev. 20, 13-25. doi: 10.1023/A:1013104423154

Regina, A., Demeule, M., Tripathy, S., Lord-Dufour, S., Currie, J. C., Iddir, M., et al. (2015). ANG4043, a novel brain-penetrant peptide-mAb conjugate, is efficacious against HER2-positive intracranial tumors in mice. Mol. Cancer Ther. 14, 129-140. doi: 10.1158/1535-7163.MCT-14-0399

Ren, H., Boulikas, T., Lundstrom, K., Soling, A., Warnke, P. C., and Rainov, N. G. (2003). Immunogene therapy of recurrent glioblastoma multiforme with a liposomally encapsulated replication-incompetent Semliki forest virus vector carrying the human interleukin-12 gene-a phase I/II clinical protocol. J. Neurooncol. 64, 147-154. doi: 10.1007/BF02700029

Roos, W. P., and Kaina, B. (2006). DNA damage-induced cell death by apoptosis. Trends Mol. Med. 12, 440-450. doi: 10.1016/j.molmed.2006.07.007

Safa, A. R., Saadatzadeh, M. R., Cohen-Gadol, A. A., Pollok, K. E., and BijangiVishehsaraei, K. (2015). Glioblastoma Stem Cells (GSCs) epigenetic plasticity and interconversion between differentiated non-GSCs and GSCs. Genes Dis. 2, 152-163. doi: 10.1016/j.gendis.2015.02.001

Sanchez-Covarrubias, L., Slosky, L. M., Thompson, B. J., Davis, T. P., and Ronaldson, P. T. (2014). Transporters at CNS barrier sites: obstacles or opportunities for drug delivery? Curr. Pharm. Des. 20, 1422-1449. doi: 10.2174/ 13816128113199990463

Santos, T., Fang, X., Chen, M. T., Wang, W., Ferreira, R., Jhaveri, N., et al. (2014). Sequential administration of carbon nanotubes and near-infrared radiation for the treatment of gliomas. Front. Oncol. 4:180. doi: 10.3389/fonc.2014. 00180

Senzer, N., Nemunaitis, J., Nemunaitis, D., Bedell, C., Edelman, G., Barve, M., et al. (2013). Phase I study of a systemically delivered p53 nanoparticle in advanced solid tumors. Mol. Ther. 21, 1096-1103. doi: 10.1038/mt.2013.32

Sharma, U. S., Sharma, A., Chau, R. I., and Straubinger, R. M. (1997). Liposomemediated therapy of intracranial brain tumors in a rat model. Pharm. Res. 14, 992-998. doi: 10.1023/A:1012136925030

Shipitsin, M., and Polyak, K. (2008). The cancer stem cell hypothesis: in search of definitions, markers, and relevance. Lab. Invest. 88, 459-463. doi: 10.1038/ labinvest.2008.14

Silber, J., Lim, D. A., Petritsch, C., Persson, A. I., Maunakea, A. K., Yu, M., et al. (2008). miR-124 and miR-137 inhibit proliferation of glioblastoma multiforme cells and induce differentiation of brain tumor stem cells. BMC Med. 6:14. doi: 10.1186/1741-7015-6-14

Singh, S. K., Hawkins, C., Clarke, I. D., Squire, J. A., Bayani, J., Hide, T., et al. (2004). Identification of human brain tumour initiating cells. Nature 432, 396-401. doi: 10.1038/nature03128

Son, M. J., Woolard, K., Nam, D. H., Lee, J., and Fine, H. A. (2009). SSEA-1 is an enrichment marker for tumor-initiating cells in human glioblastoma. Cell Stem Cell 4, 440-452. doi: 10.1016/j.stem.2009.03.003

Stupp, R., Hegi, M. E., Mason, W. P., van den Bent, M. J., Taphoorn, M. J., Janzer, R. C., et al. (2009). Effects of radiotherapy with concomitant and adjuvant temozolomide versus radiotherapy alone on survival in glioblastoma in a randomised phase III study: 5-year analysis of the EORTC-NCIC trial. Lancet Oncol. 10, 459-466. doi: 10.1016/S1470-2045(09)70025-7

Stupp, R., Mason, W. P., van den Bent, M. J., Weller, M., Fisher, B., Taphoorn, M. J., et al. (2005). Radiotherapy plus concomitant and adjuvant temozolomide for glioblastoma. N. Engl. J. Med. 352, 987-996. doi: 10.1056/NEJMoa 043330

Su, Y. J., Lin, W. H., Chang, Y. W., Wei, K. C., Liang, C. L., Chen, S. C., et al. (2015). Polarized cell migration induces cancer type-specific CD133/integrin/Src/Akt/GSK3beta/beta-catenin signaling required for maintenance of cancer stem cell properties. Oncotarget 6, 38029-38045. doi: 10.18632/oncotarget.5703

Su, Z. Z., Sarkar, D., Emdad, L., Duigou, G. J., Young, C. S., Ware, J., et al. (2005). Targeting gene expression selectively in cancer cells by using the progressionelevated gene-3 promoter. Proc. Natl. Acad. Sci. U.S.A. 102, 1059-1064. doi: 10.1073/pnas.0409141102

Sun, T., Chen, G., Li, Y., Xie, X., Zhou, Y., and Du, Z. (2015). Aggressive invasion is observed in CD133-/A2B5+ glioma-initiating cells. Oncol. Lett. 10, 3399-3406. doi: 10.3892/ol.2015.3823OL-0-0-3823 
Tchoghandjian, A., Baeza, N., Colin, C., Cayre, M., Metellus, P., Beclin, C., et al. (2010). A2B5 cells from human glioblastoma have cancer stem cell properties. Brain Pathol. 20, 211-221. doi: 10.1111/j.1750-3639.2009.00269.x

Thomas, F. C., Taskar, K., Rudraraju, V., Goda, S., Thorsheim, H. R., Gaasch, J. A., et al. (2009). Uptake of ANG1005, a novel paclitaxel derivative, through the blood-brain barrier into brain and experimental brain metastases of breast cancer. Pharm. Res. 26, 2486-2494. doi: 10.1007/s11095-009-9964-5

Tzeng, S. Y., and Green, J. J. (2013). Subtle changes to polymer structure and degradation mechanism enable highly effective nanoparticles for siRNA and DNA delivery to human brain cancer. Adv Healthc. Mater. 2, 468-480. doi: 10.1002/adhm.201200257

Upadhyay, R. K. (2014). Drug delivery systems, CNS protection, and the blood brain barrier. Biomed Res. Int. 2014:869269. doi: 10.1155/2014/869269

Van Houdt, W. J., Haviv, Y. S., Lu, B., Wang, M., Rivera, A. A., Ulasov, I. V., et al. (2006). "The human survivin promoter: a novel transcriptional targeting strategy for treatment of glioma. J. Neurosurg. 104, 583-592. doi: 10.3171/jns. 2006.104.4.583

Velpula, K. K., Rehman, A. A., Chelluboina, B., Dasari, V. R., Gondi, C. S., Rao, J. S., et al. (2012). Glioma stem cell invasion through regulation of the interconnected ERK, integrin alpha6 and N-cadherin signaling pathway. Cell. Signal. 24, 2076-2084. doi: 10.1016/j.cellsig.2012.07.002

von Holst, H., Knochenhauer, E., Blomgren, H., Collins, V. P., Ehn, L., Lindquist, M., et al. (1990). Uptake of adriamycin in tumour and surrounding brain tissue in patients with malignant gliomas. Acta Neurochir. 104, 13-16. doi: 10.1007/BF01842886

Wakabayashi, T., Natsume, A., Hashizume, Y., Fujii, M., Mizuno, M., and Yoshida, J. (2008). A phase I clinical trial of interferon-beta gene therapy for high-grade glioma: novel findings from gene expression profiling and autopsy. J. Gene Med. 10, 329-339. doi: 10.1002/jgm.1160

Wang, C. H., Chiou, S. H., Chou, C. P., Chen, Y. C., Huang, Y. J., and Peng, C. A. (2011). Photothermolysis of glioblastoma stem-like cells targeted by carbon nanotubes conjugated with CD133 monoclonal antibody. Nanomedicine 7, 69-79. doi: 10.1016/j.nano.2010.06.010

Wang, J., Sakariassen, P. O., Tsinkalovsky, O., Immervoll, H., Boe, S. O., Svendsen, A., et al. (2008). CD133 negative glioma cells form tumors in nude rats and give rise to CD133 positive cells. Int. J. Cancer 122, 761-768. doi: $10.1002 /$ ijc. 23130

Westphal, M., and Lamszus, K. (2011). The neurobiology of gliomas: from cell biology to the development of therapeutic approaches. Nat. Rev. Neurosci. 12, 495-508. doi: 10.1038/nrn3060

Weyerbrock, A., Walbridge, S., Pluta, R. M., Saavedra, J. E., Keefer, L. K., and Oldfield, E. H. (2003). Selective opening of the blood-tumor barrier by a nitric oxide donor and long-term survival in rats with C6 gliomas. J. Neurosurg. 99, 728-737. doi: 10.3171/jns.2003.99.4.0728

Weyerbrock, A., Walbridge, S., Saavedra, J. E., Keefer, L. K., and Oldfield, E. H. (2011). Differential effects of nitric oxide on blood-brain barrier integrity and cerebral blood flow in intracerebral C6 gliomas. Neuro Oncol. 13, 203-211. doi: 10.1093/neuonc/noq161

Wolburg, H., Wolburg-Buchholz, K., Kraus, J., Rascher-Eggstein, G., Liebner, S., Hamm, S., et al. (2003). Localization of claudin-3 in tight junctions of the blood-brain barrier is selectively lost during experimental autoimmune encephalomyelitis and human glioblastoma multiforme. Acta Neuropathol. 105, 586-592. doi: 10.1007/s00401-003-0688-Z

Xu, R., Ma, J., Sun, X., Chen, Z., Jiang, X., Guo, Z., et al. (2009). Ag nanoparticles sensitize IR-induced killing of cancer cells. Cell Res. 19, 1031-1034. doi: 10.1038/ cr.2009.89

Xu, Y., Stamenkovic, I., and Yu, Q. (2010). CD44 attenuates activation of the hippo signaling pathway and is a prime therapeutic target for glioblastoma. Cancer Res. 70, 2455-2464. doi: 10.1158/0008-5472.CAN-09-2505

Yang, Z. F., Ho, D. W., Ng, M. N., Lau, C. K., Yu, W. C., Ngai, P., et al. (2008). Significance of CD90+ cancer stem cells in human liver cancer. Cancer Cell 13, 153-166. doi: 10.1016/j.ccr.2008.01.013

Ying, X., Wen, H., Lu, W. L., Du, J., Guo, J., Tian, W., et al. (2010). Dualtargeting daunorubicin liposomes improve the therapeutic efficacy of brain glioma in animals. J. Control. Release 141, 183-192. doi: 10.1016/j.jconrel.2009. 09.020

Yoshida, J., Mizuno, M., Fujii, M., Kajita, Y., Nakahara, N., Hatano, M., et al. (2004). Human gene therapy for malignant gliomas (glioblastoma multiforme and anaplastic astrocytoma) by in vivo transduction with human interferon beta gene using cationic liposomes. Hum. Gene Ther. 15, 77-86. doi: 10.1089/ 10430340460732472

Yu, W., Pirollo, K. F., Rait, A., Yu, B., Xiang, L. M., Huang, W. Q., et al. (2004). A sterically stabilized immunolipoplex for systemic administration of a therapeutic gene. Gene Ther. 11, 1434-1440. doi: 10.1038/sj.gt.33023043302304

Zeng, X., Han, I., Abd-El-Barr, M., Aljuboori, Z., Anderson, J. E., Chi, J. H., et al. (2016). The effects of thermal preconditioning on oncogenic and intraspinal cord growth features of human glioma cells. Cell Transplant. 25, 2099-2109. doi: 10.3727/096368916X691493

Zheng, Y., Hunting, D. J., Ayotte, P., and Sanche, L. (2008). Radiosensitization of DNA by gold nanoparticles irradiated with high-energy electrons. Radiat. Res. 169, 19-27. doi: 10.1667/RR1080.1

Zhu, X. Y., Wang, L., Luan, S. H., Zhang, H. S., Huang, W. T., and Wang, N. H. (2014). The PGI-KLF4 pathway regulates self-renewal of glioma stem cells residing in the mesenchymal niches in human gliomas. Neoplasma 61, 401-410. doi: 10.4149/neo_2014_049

Zucchetti, M., Boiardi, A., Silvani, A., Parisi, I., Piccolrovazzi, S., and D'incalci, M. (1999). Distribution of daunorubicin and daunorubicinol in human glioma tumors after administration of liposomal daunorubicin. Cancer Chemother. Pharmacol. 44, 173-176. doi: 10.1007/s002800050964

Conflict of Interest Statement: The authors declare that the research was conducted in the absence of any commercial or financial relationships that could be construed as a potential conflict of interest.

Copyright (c) 2017 Glaser, Han, Wu and Zeng. This is an open-access article distributed under the terms of the Creative Commons Attribution License (CC BY). The use, distribution or reproduction in other forums is permitted, provided the original author(s) or licensor are credited and that the original publication in this journal is cited, in accordance with accepted academic practice. No use, distribution or reproduction is permitted which does not comply with these terms. 